\title{
ECHOCARDIOGRAPHIC CHANGES FOLLOWING RABBIT CORONAVIRUS INFECTION
}

\author{
Lorraine K. Alexander, Bruce W. Keene, and Ralph S. Baric \\ The Department of Epidemiology \\ The University of North Carolina at Chapel Hill \\ Chapel Hill, North Carolina \\ The College of Veterinary Medicine \\ North Carolina State University \\ Raleigh, North Carolina
}

Much of our understanding of the mechanisms by which viruses cause myocarditis and/or dilated cardiomyopathy (DCM) is based on animal models of virus-induced heart disease. Information concerning cardiac function during acute and/or chronic viral infection in these models is limited (1). A well defined model in a species conducive to monitoring of cardiac function is needed to enhance our understanding of viral induced heart disease. We have previously demonstrated that rabbit coronavirus ( $\mathrm{RbCV}$ ) infection results in degeneration and necrosis of myocytes, myocarditis, and gross organ and histopathologic changes of $\operatorname{DCM}(2,3)$. We have also shown that electrocardiographic changes observed during RbCV infection mimic those in humans with myocarditis and DCM (submitted). This chapter describes the echocardiographic changes observed during RbCV infection.

Eleven male New Zealand white rabbits were sedated prior to echocardiography with a combination of xylazine $(0.17 \mathrm{mg} / \mathrm{kg})$ and ketamine $(17 \mathrm{mg} / \mathrm{kg})$. An electrocardiogram was monitored continuously during echocardiography and two-dimensional echocardiographic views were recorded with the animal in right lateral recumbancy from the right parasternal long and short-axis positions using a $7.5 \mathrm{MHz}$ annular array transducer. Measurements of left ventricular (LV) size, systolic function, mitral valve motion, and aortic and left atrial diameter were made according to the American Society of Echocardiography standards for M-mode echocardiography. Briefly, M-mode measurements included LV end diastolic and systolic chamber dimensions and wall thickness obtained by guiding the M-mode cursor between the papillary muscles from a right parasternal short-axis imaging plane just ventral to the mitral valve leaflets at the level of the chordae tendinae. Aortic and left atrial dimensions were measured from an M-mode view obtained by guiding the cursor through the aorta and left atrium in a right parasternal short short axis view at the level of the aortic valve. The mitral valve motion and E-point - septal separation was observed and recorded from $\mathrm{M}$-mode images obtained by guiding the cursor through a right parasternal 
Table 1. Cardiac function values for $11 \mathrm{RbCV}$ infected rabbits

\begin{tabular}{|c|c|c|c|}
\hline Measurement & $\begin{array}{c}\text { Uninfected }^{\mathrm{a}} \\
\mathrm{n}=11\end{array}$ & $\begin{array}{c}\text { Nonsurvivor }{ }^{\mathrm{a}, \mathrm{b}} \\
\mathrm{n}=6\end{array}$ & $\begin{array}{c}\text { Suvivor }^{\mathrm{a}, \mathrm{b}} \\
\mathrm{n}=5\end{array}$ \\
\hline Left Ventricular $(\mathrm{LV})$ diameter $(\mathrm{d})^{\mathrm{c}}(\mathrm{cm})$ & $1.42 \pm 0.24$ & $1.13 \pm 0.44$ & $1.14 \pm 0.12$ \\
\hline LV diameter $(\mathrm{s})^{\mathrm{d}}(\mathrm{cm})$ & $0.92 \pm 0.17$ & $0.93 \pm 0.38$ & $0.84 \pm 0.17$ \\
\hline$\%$ fractional shortening & $35.5 \pm 4.85$ & $17.33 \pm 6.19$ & $26.17 \pm 12$ \\
\hline Septal wall thickness $(\mathrm{d})(\mathrm{cm})$ & $0.22 \pm 0.07$ & $0.25 \pm 0.06$ & $0.22 \pm 0.05$ \\
\hline Septal wall thickness $(\mathrm{s})(\mathrm{cm})$ & $0.38 \pm 0.08$ & $0.28 \pm 0.09$ & $0.33 \pm 0.12$ \\
\hline LV posterior wall thickness $(\mathrm{d})(\mathrm{cm})$ & $0.31 \pm 0.11$ & $0.32 \pm 0.08$ & $0.26 \pm 0.03$ \\
\hline LV posterior wall thickness $(\mathrm{s})(\mathrm{cm})$ & $0.50 \pm 0.12$ & $0.44 \pm 0.13$ & $0.42 \pm 0.06$ \\
\hline Left atrium diamter $(\mathrm{cm})$ & $0.88 \pm 0.14$ & $0.93 \pm 0.15$ & $0.86 \pm 0.10$ \\
\hline Aorta $(\mathrm{cm})$ & $0.66 \pm 0.12$ & $0.74 \pm 0.13$ & $0.68 \pm 0.05$ \\
\hline Left atrium/Ao & $1.22 \pm 0.20$ & $1.36 \pm 0.39$ & $1.28 \pm 0.14$ \\
\hline E point septal separation (EPSS) & $0.14 \pm 0.04$ & $0.22 \pm 0.16$ & $0.126 \pm 0.09$ \\
\hline
\end{tabular}

$\mathrm{a}=$ Mean \pm SD.

$\mathrm{b}=$ Day 3 after infection.

$\mathrm{c}=$ diastole.

$\mathrm{d}=$ systole.

short axis view at the level of the mitral valve. LV fractional shortening was calculated as an ejection phase index of systolic function. All values reported reflect the mean of 3 measurements made on sinus beats. Rabbits were infected with $0.3 \mathrm{ml}$ of a $1 \mathrm{X} 10^{3}-1 \mathrm{X} 10^{4}$ $\mathrm{RID}_{50}$ of RbCV and echocardiographic measurements were repeated using the same anesthetic and measurement protocol on days $3,6,9,12$ and 30 post-infection.

Two (18\%) rabbits died during the acute phase of infection (day 3), $4(36 \%$ ) died in the early subacute phase (day 6), and 5 (46\%) survived beyond day 12 into the chronic phase. Echocardiographic data is displayed in Table 1. The index of systolic ventricular function

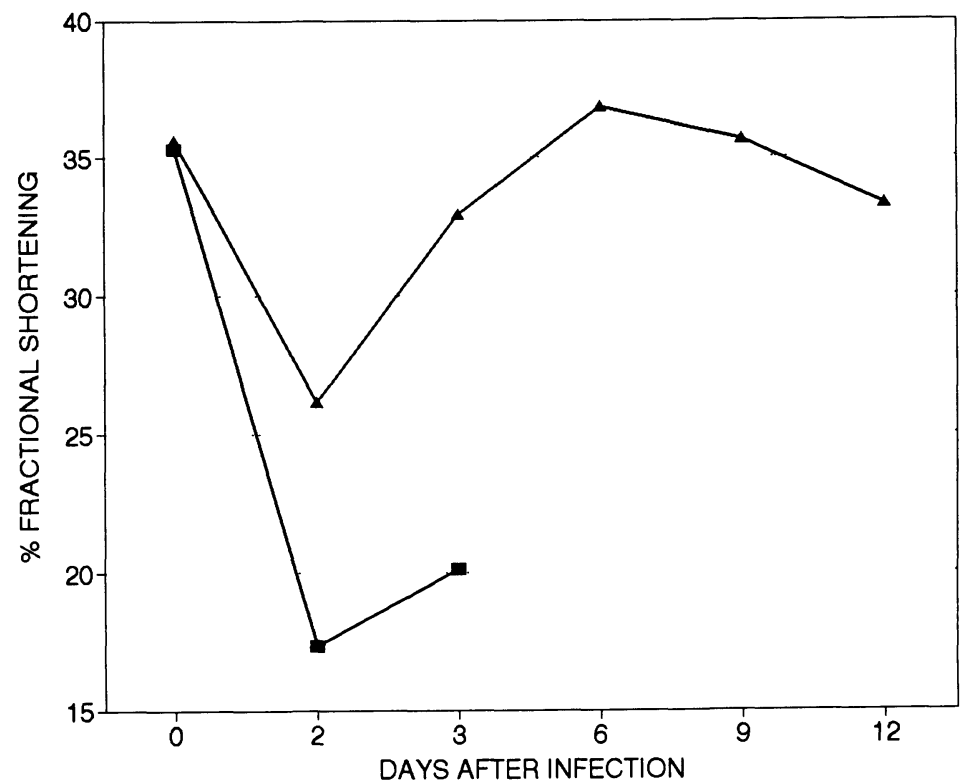

Figure 1. Percent fractional shortening in $11 \mathrm{RbCV}$ infected rabbits. 
chosen, $\%$ fractional shortening was depressed in all infected rabbits by day 3 post infection (Figure 1). Fractional shortening was more depressed in nonsurvivors $(17.33 \pm 6.19 \%, p=$ $<.001$ from controls) as compared to survivors $(26.17 \pm 12 \%$, ns from control). Mean LV wall thickness, chamber dimensions, and left atrial dimensions were not significantly different from controls throughout the study in either survivors or nonsurvivors. These findings confirm our previous pathologic studies in which rabbits dying early in infection (days 2-5) did not have significantly different LV wall thickness, and chamber dimensions from control animals.

We conclude that RbCV infection depresses an ejection phase index of systolic LV function, that this depression precedes gross morphologic changes in the ventricle, and that severe systolic dysfunction correlates positively with mortality. These findings provide a direct link between the severity of virus-induced cardiac dysfunction and survival during $\mathrm{RbCV}$ infection, characterizing a reproducible model of cardiac dysfunction following viral infection of the heart.

\section{REFERENCES}

1. Woodruff JF. Am J Pathol 1980;101:427-84.

2. Edwards S. et al. J Infect Dis 1992;165:134-40.

3. Alexander LK. et al. J Infect Dis 1992;166:978-85 